\title{
Community pharmacy in Tangail region of Bangladesh: Current impression
}

\author{
Israt Jahan Ira ${ }^{1 *}$, Md Akib Jahan ${ }^{2}$, Effat Jahan $\mathrm{Eva}^{3}$, Sayema Arefin ${ }^{1}$ \\ ${ }^{1}$ Department of Pharmacy, Mawlana Bhashani Science and Technology University, Santosh, \\ Tangail- 1902, Bangladesh. \\ ${ }^{2}$ MD resident (Cardiology), Sir Salimullah Medical College and Mitford Hospital, Dhaka, \\ Bangladesh. \\ ${ }^{3}$ FCPS Part-2 trainee, Department of Obstetrics and Gynaecology, Sir Salimullah Medical \\ College and Mitford Hospital, Dhaka, Bangladesh
}

Received: 04-08-2021 / Revised Accepted: 28-08-2021 / Published: 01-09-2021

\begin{abstract}
Community pharmacists are the health professionals most accessible to the public. They supply medicines in accordance with a prescription or, when legally permitted, sell them without a prescription. The current study was conducted to reveal the present condition of community pharmacy in Tangail, Bangladesh and for these 25 retail pharmacies were visited. From the study it is clear that the sector of community pharmacy is so deferred and yet to be developed in this country. There is scarcity of professionals and the sector is mostly dependent on $\mathrm{B}$ and $\mathrm{C}$ grade pharmacists. There was no ' $\mathrm{A}$ ' grade pharmacist found in this study, $5 \%$ of them are ' $\mathrm{B}$ ' grade who completed 3 months diploma course and $95 \%$ of them are ' $\mathrm{C}$ ' grade pharmacists who rarely did a 3-4 months course. $12 \%$ of the pharmacists are very aged and it is very risky to depend on them. $74 \%$ of the pharmacist's counsel patients without any prescription and among them $70 \%$ suggest antibiotics which is very alarming. $87.5 \%$ of them give sedative drugs without any prescription. Appropriate measures should be taken to improve the present scenario of Community pharmacy in Bangladesh.
\end{abstract}

Key words: Community Pharmacy, Bangladesh, antibiotics, sedatives

\section{INTRODUCTION}

Pharmacy is one of the oldest professions with a history dating back to 2700BC. Pharmacy practice was initially combined with medicine but it was not until 1200AD that pharmacy became legally separated from medicine ${ }^{[1-2]}$. Community pharmacists usually work in the high street, local and rural pharmacies. They are involved in the sale and supply of medicines and give advice about medicines, symptoms and general health matters. They are responsible for dispensing medicines,

Address for Correspondence: Israt Jahan Ira, Assistant Professor, Department of Pharmacy, Mawlana Bhashani Science and Technology University, Santosh, Tangail- 1902, Bangladesh; Email: ira.israt@mbstu.ac.bd

How to Cite this Article: Israt Jahan Ira, Md Akib Jahan, Effat Jahan Eva, Sayema Arefin. Community pharmacy in Tangail region of Bangladesh: Current impression. World J Pharm Sci 2021; 9(9): 15159.

This is an open access article distributed under the terms of the Creative Commons Attribution-NonCommercialShareAlike 4.0 International License, which allows adapt, share and build upon the work non-commercially, as long as the author is credited and the new creations are licensed under the identical terms. (cc) EY-NC-SA 
counsel patients on their proper use and other prescribers that dosages are correct, and check that new treatments are compatible with other medicines the patient may be taking ${ }^{[3]}$. Community pharmacies have quite a distinct and unique position in healthcare delivery system as they are the first and/or final contacts between patients and drugs in majority of cases ${ }^{[4]}$. Community pharmacy practice therefore has a major impact on the public perception of the pharmacy profession. In the United States of America, Britain, and some European countries, standards of practice are well defined and details of community pharmacy practice are highly predictable ${ }^{[5]}$. The concept and services provided by community pharmacy in Bangladesh is far different from the developed countries. Most of the retail and community pharmacies in Bangladesh are run by the people who have not even completed the 3 months pharmacy registration certificate course ${ }^{[6]}$. The most common causes of irrational use of drugs are lack of information, imperfect and insufficient training and education of medical graduates, poor communication between health professionals and patients, lack of diagnostic facilities or uncertainty of diagnosis, demand from patient, defective drug supply or ineffective drug regulation, and promotional activities of pharmaceutical industries $^{[7]}$. Numerous studies have confirmed that pharmacist involvement in patient care can improve patient outcomes and reduce costs ${ }^{[8]}$.

\section{MATERIALS AND METHODS}

Methodological approach: A cross sectional study using a validated questionnaire was conducted in 25 retail pharmacy in Shantikunja road, Victoria road, Akur Takurpara and new bus stand area of Tangail Town, Bangladesh from July to September, 2019. The pharmacists present in pharmacy were interviewed properly with their consent. 200 prescriptions were also analyzed.

Study frame: At first four main region of Tangail town were chosen randomly on basis of the number of pharmacy present in that area. A cover letter about the aims of the study was given to the pharmacy in charge for his permission. Study participants include both gender and age above 18 years old.

Study tool: The questionnaire was designed with 3 parts. Part 1 encompasses demographic data (gender, age, educational levels, monthly income levels, Part 2 consists of the information about the pharmacists, patient and prescribed drugs and part 3 contains the information about the condition of the pharmacy.

\section{RESULT}

25 retail pharmacies were visited for this study. 40 pharmacists were questioned about their current profession status. From them some are very new and inexperienced, $7.5 \%$ of them are working for less than 1 year, $67.5 \%$ working for more than 5 years and $10 \%$ of them are working for more than 10 years. Some of them are very aged and working for more than $25(5 \%)$ years.

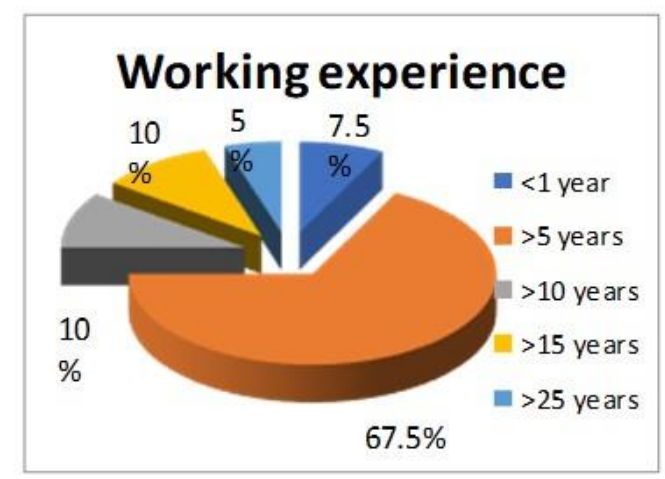

Figure 1: Working years of the pharmacists.

In the study we found only $5 \%$ of $\mathrm{B}$ grade pharmacists and rests of them are $\mathrm{C}$ grade pharmacists. It's a matter of great regret that we found no A grade pharmacists during the study.

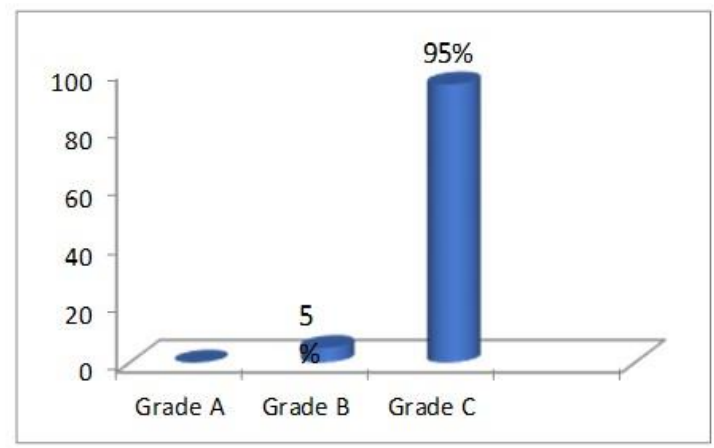

Figure 2: Different grades of pharmacist among the respondents.

The demographic data shows that, the average age of the pharmacists was 31.5 years. Among the 40 pharmacists $15 \%$ completed their graduation whereas $67.5 \%$ and $17.5 \%$ completed H.S.C and S.S.C respectively.

Participating pharmacists were asked some questions regarding their works like what are the common diseases for which patient seeks advice, what are the commonly suggested drugs etc. $75 \%$ of the pharmacies provide BP measurement, nebulizer and blood glucose level measurement. $75 \%$ of the pharmacists work alone which create a lot of pressure on them and inhibit them to give a satisfactory and safe service. 


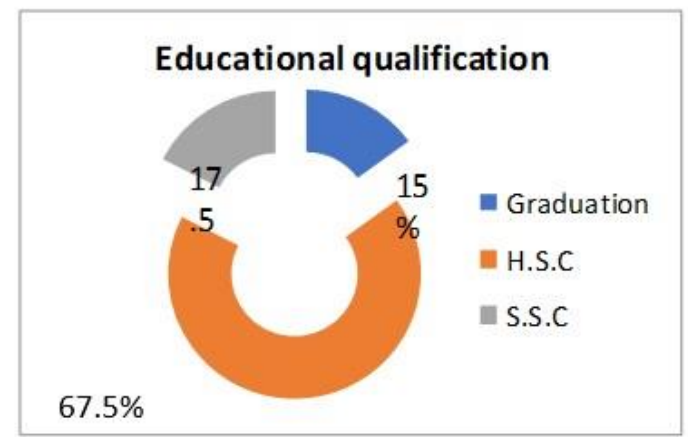

Figure 3: Educational qualification of the respondents

$100 \%$ of them think that patient counseling is the duty of a doctor not of a pharmacist. But it is found that $100 \%$ of them also suggest drug without prescription. $37.5 \%$ of them never check the medical history of the patient and $45 \%$ of them check sometime. $70 \%$ of them sell antibiotics and $87.5 \%$ of them sell sedative drugs without prescription. Only $15 \%$ of them explain the diagnostic results to the patients. $55 \%$ of them explain the information regarding the drug like time, route of taking drug etc. $37.5 \%$ of them don't provide information regarding the side effects of the prescribed drug. $97.5 \%$ of the pharmacies don't keep any documents regarding patient's information or memos. $25 \%$ of the pharmacies provide complementary packs for elderly patients so that they can keep the drugs and don't mix them with one another. Most interestingly $79 \%$ of the respondents thought there were no need to make any improvement in their jobs, they are happy what they were giving. Whereas, $15.5 \%$ of them thought the job should be improved and it is only possible if the facilities of the pharmacy will be enhanced.

\section{DISCUSSION}

In most developed countries, compulsory presence of a pharmacist is the norm whenever the Pharmacy is opened to the public ${ }^{[9-11]}$. The situation is however different in developing countries despite legislation to that effect. Poor adherence to medication is a major problem among patients with chronic diseases ${ }^{[12]}$. Community pharmacists have greater role in the health care delivery to the community. Community pharmacists can act as first point of contact health care provider. But it is a matter of great regret that the current scenario of community pharmacist in Bangladesh is very poor.
We conduct this study in Tangail district of Bangladesh. 40 pharmacists were being brought under this study. No A grade pharmacist was found during this study. Maximum pharmacies were operated by very lower educational quality persons with a negligible amount of drug knowledge. One of the main responsibilities of community pharmacists is to consult with physician and nurses for providing better healthcare facility to the patients $^{[13]}$.

Patient's safety greatly depends upon pharmacists as they read the prescription and sell drugs. In this study $75 \%$ of the pharmacist working alone expose the chance of doing mistakes when there is a lot of patients in the pharmacy. Drug response, efficacy and toxicity may be influenced on previous medical history of that patient, but only $12.5 \%$ of the pharmacists check the previous records which is very threatening. All of the pharmacists under this study practice to give drug without prescription and among them $70 \%$ give antibiotics and $75 \%$ give sedative drugs. Maximum of them $(85 \%)$ are not even interested to explain the diagnostic test results to the patient.

It is essential to maintain sales memos with patients name and address, batch number of the medicines sold, as a legal requirement and to safeguard themselves in the event of any drug found substandard or unsafe requiring recall etc. But only $2.5 \%$ of them do this according to our study. However this is the current scenario of Tangail district which essentially may not represent the overall situation of Bangladesh. Further study will be conduct to assay the situation more precisely.

\section{CONCLUSION}

From the current study it can be said that the community pharmacy sector in Bangladesh are much deferred from that of other developing countries and we must take steps to reduce the difference. As the study shows that the persons working in this area are mostly not highly educated and this sector should be operated by professionally skilled persons, so provision should be made that only skilled persons will operate the sector. In some pharmacies there are some aged persons also who are unable to see things correctly, it can make some dangerous mistakes too. Govt. should prepare some specific laws and requirements for this sector if we want to walk with developed countries.

\section{Reference}

1. Anderson S: Making Medicines-A brief history of pharmacy and pharmaceuticals., The Pharmaceutical Press, $1^{\text {st }}$ edition, London, 2005.

2. Adenika FB: Pharmacy in Nigeria Panpharm Ltd., Lagos Nigeria, 1998.

3. Caamaño F, Ruano A, Figueiras A, Gestal-Otero JJ: Data collection methods for analyzing the quality of the dispensing in pharmacies. Pharmacy World \& Science. 2002; 24:217-23, 
4. A. Hafeez: Prescription and Dispensing Practices in Public Sector Health Facilities in Pakistan: Survey Report. Journal of Pakistan Medical Association. 2004; 54(4):187-191.

5. Department of Health; Pharmacy in England Building Strengths-Delivering the future. Available from http/wwwdh.gov.uk.

6. Zubair KL, Razia S, Md. Abdul B, Krishanu S, Khurshid J: A close supervision of pharmacy practice by community pharmacists in Dhaka city, Bangladesh. Journal of Drug Discovery and Therapeutics2013; 1(3): 105-111.

7. Streatfield P.K. and Karar Z: A Population challenges for Bangladesh in the coming decades. Journal of Health Population and Nutrition 2008; 26:261-272.

8. Laing R: Role of dispensers in Promoting Rational Drug Use.

http://dcc2.bumc.bu.edu/prdu/Session_Guides/ role_of_dispensers_in_rational_d.htm Reached: $22^{\text {nd }}$ Dec, 2009 in September 1996.

9. Parmar S: Community pharmacy practice in the United States and Kenya- Comparison. Diabetes in Control 2008, Issue 406, Available from http// www diabetes in control.com.

10. Iguchi S, Ohnishi M, Nishiyanma T Hosonack, Umezawa C: Community Pharmacy Practice in Japan Results of a Survey. Journal of Clinical Pharmacy and. Therapeutics 1998; 3:233-237.

11. Foppe vann mil JW, Martin Schulz; A review of pharmaceutical care in community pharmacy in Europe. Harvard Health Policy Review. 2006; 7(1):155-161.

12. Martin, LR, Williams, SL, Haskard, KB. and DiMatteo, MR. The challenge of patient adherence. Journal of Therapeutics and Clinical. Risk Management 2005; 1: 189-199.

13. Albanese NP, Rouse MJ and Council on Credentialing in Pharmacy: Scope of contemporary pharmacy practice: roles, responsibilities, and functions of pharmacists and pharmacy technicians. Journal of American Pharmacists Association. 2010; 50:35-69 